\title{
Prevention of Venous Thromboembolism in General Surgery at Gabriel Touré University Hospital in Mali
}

\author{
Amadou Traoré*, Madiassa Konaté, Abdoulaye Diarra, Koniba Keïta, Kadia Traoré, \\ Zakari Saye, Youssouf Koné, Boubacar Yoro Sidibé, Amadou Maïga, Amadou Bah, \\ Bouréima Kelly, Tani Koné, Boubacar Karembé, Souleymane Thiam, Assitan Koné, \\ Drissa Bagayogo, Bakary Tientigui Dembélé, Alhassane Traoré, Ibrahim Diakité, \\ Lassana Kanté, Adégné Togo
}

Gabriel Touré University Hospital, Bamako, Mali

Email: *amadoutra242@gmail.com

How to cite this paper: Traoré, A., Konaté, M., Diarra, A., Keïta, K., Traoré, K., Saye, Z., Koné, Y., Sidibé, B.Y., Maïga, A., Bah, A., Kelly, B., Koné, T., Karembé, B., Thiam, S., Koné, A., Bagayogo, D., Dembélé, B.T., Traoré, A., Diakité, I., Kanté, L. and Togo, A. (2021) Prevention of Venous Thromboembolism in General Surgery at Gabriel Touré University Hospital in Mali. Surgical Science, 12, 67-75.

https://doi.org/10.4236/ss.2021.123009

Received: February 8, 2021

Accepted: March 19, 2021

Published: March 22, 2021

Copyright ( 2021 by author(s) and Scientific Research Publishing Inc. This work is licensed under the Creative Commons Attribution International License (CC BY 4.0).

http://creativecommons.org/licenses/by/4.0/ (c) (i) Open Access

\begin{abstract}
Through its impact on morbidity and mortality and the cost of medical care, Venous Thromboembolism (VTE) has a significant influence on the quality of care in a surgical environment. The objectives were to determine the risk of postoperative venous thromboembolism and to assess its prophylactic management in the general surgery department of Gabriel Toure University Hospital. This was a prospective observational study from May 01, 2018 to December 31, 2018. It included all patients of 18 years old and over, operated in regulated surgery, under general anesthesia in the department. For all of these patients, Caprini score was used to assess the risk of VTE. The ninth American College of Chest Physicians' Consensus was used as guidelines to assess Thromboprophylaxis practices in the ward. The Caprini score was evaluated in 80 patients for 8 months. The average age was 50.2 years. The sex ratio was 0.48 . The risk level of VTE was low in three patients (3.8\%), moderate in 13 patients (16.3\%), high in 34 patients $(42.5 \%)$ and highest in 30 patients $(37.5 \%)$. The main risk factors found were major surgery $(87.5 \%)$, age $>40$ years $(72.5 \%)$, cancer $(33.8 \%)$, bed rest $(31.2 \%)$, obesity (27.5\%) and minor surgery (12.5\%). Early mobilization was performed in all patients. Pharmacologic prophylaxis was required in $80 \%$ of our patients but only $38.8 \%$ had received low molecular weight heparin. VTE complicated 5 procedures, including 3 cases of deep vein thrombosis of the limbs and 2 cases of pulmonary embolism who died. Venous thromboembolism is serious and common in surgical settings. Its prevention remains insufficient in our context.
\end{abstract}




\section{Keywords}

Venous Thromboembolism, Prevention, Surgery, Mali

\section{Introduction}

Venous Thromboembolism (VTE) is the entity bringing together the Deep Vein Thrombosis (DVT) and Pulmonary Embolism (PE) and is therefore equivalent to a set of thromboembolic events. It is a frequent, multifactorial and serious condition. The overall thromboembolic risk is the result of the patient's risk and the risk specific to the intervention [1]. The prevalence of the risk of VTE in surgery has been estimated at $64.4 \%$ worldwide and $65 \%$ to $78 \%$ in Europe and the United States, according to the multinational ENDORSE study in 2008 [2] [3]. In sub-Saharan Africa, the proportion of surgical patients at risk for VTE ranged from $22 \%$ to $73 \%$ [4] [5]. A patient undergoing major surgery has a 20 -fold risk of VTE and this risk is increased by $30 \%$ when there is no optimal prophylaxis [6] [7]. Through its impact on morbidity and mortality and the cost of medical care, Venous Thromboembolism (VTE) has a significant influence on the quality of care in a surgical environment. Mortality ranges from $1 \%$ to $5 \%$ in patients with highest risk level of VTE [8]. Assessment of the risk of VTE in operated patients and thromboprophylaxis are therefore essential. Despite the high prevalence of VTE risk factors, only $58.5 \%$ of surgical patients in the world received thromboprophylaxis. Studies on the risks of VTE in surgery are few in sub-Saharan Africa and thromboprophylaxis is very often considered insufficient. It was performed in only $28.5 \%$ of at-risk surgical patients in Benin [5], and in less than $50 \%$ in Nigeria, Botswana and Madagascar [4]. The objectives of this study were: to determine the risk of postoperative venous thromboembolism and to assess its prophylactic management in the general surgery department of Gabriel Toure University Hospital.

\section{Methodology}

This was an 8-month prospective observational study, running from May 01 to December 31, 2018. It included all patients of 18 years old and over, operated in regulated surgery, under general anesthesia in the department. This was a comprehensive sample of all patients, on condition of anonymity, meeting the above criteria and having given their consent. The patient was recruited upon discharge. The data were collected on a previously validated form, from medical files and operating report registers. These files were consulted at 2 periods: on discharge from the hospital and 30 days after the surgery. This form included demographic data, those relating to thromboembolic and hemorrhagic risks, thromboprophylaxis, surgical outcomes and length of hospitalization. The Caprini score [8] was used to assess the risk level of VTE. The risk was low for a score of 0 or 1 , moderate for a score of 2 , high for a score of 3 or 4 , and highest 
for a score of 5 or more. The ninth American College of Chest Physicians' (ACCP) Consensus [9] was used as guidelines to assess Thromboprophylaxis practices in the ward.

Data analysis was performed on Excel 2016 and IBM SPSS Statistics 20.0 software. The statistical tests used were Chi-square, Fischer's exact test with a significance level $\mathrm{p}<0.05$.

\section{Results}

We evaluated the Caprini score in 80 patients who underwent surgery, corresponding to $32 \%$ of surgical operations and $15.32 \%$ of hospitalizations. The mean age of patients was 50.2 years with a standard deviation of 13.95 and ranges between 18 and 80 years. The sex ratio was 0.48 . Sociodemographic data have been reported in Table 1.

According to the Caprini score, the risk of VTE was low in three patients (3.8\%), moderate in 13 patients (16.3\%), high in 34 patients (42.5\%) and highest in 30 patients $(37.5 \%)$. The parameters of this score found in patients were reported in Table 2. The main risk factors found were major surgery (87.5\%), age $>40$ years $(72.5 \%)$, cancer $(33.8 \%)$, bed rest $(31.2 \%)$, obesity $(27.5 \%)$ and minor surgery (12.5\%); Other risk factors accounted for $1 \%-3 \%$ each. A hemorrhagic risk was found in 04 patients (5\%). The surgeries performed were reported in Table 3. These were mainly: gastric (25\%), colorectal (18.8\%), gyneco-mammary (13.8\%), thyroid (12.5\%), laparoscopic (12.5\%), hepatobiliary (8.7\%), Parietal (8.7\%) and spleno-pancreatic (7.5\%). The mean length of hospital stay was $7.17 \pm 6.38$ days and extremes of 1 and 53 days.

The prophylactic measures practiced in the department were: early mobilization of patients in $92.5 \%$ (74 patients) and prophylaxis with low molecular weight heparin (LMWH), Enoxaparin in 31 patients (38.8\%). Thromboprophylaxis performed according to VTE's risk level was reported in Table 4. The mean duration of thromboprophylaxis was 3.4 days with extremes of 1 and 10 days. The 30 -day postoperative outcomes (Table 5) were simples in $92.5 \%$. Five patients

Table 1. Socio-demographic characteristics.

\begin{tabular}{ccc}
\hline Variable & Effectives & Percentage \\
\hline 40 & Age (years) & \\
\hline $40-60]$ & 22 & 27.5 \\
$160-75]$ & 39 & 48.8 \\
$>75$ & 16 & 20 \\
Total & 03 & 3.8 \\
& 80 & 100 \\
Male & Gender & 32.5 \\
Female & 26 & 67.5 \\
Total & 54 & 100 \\
\hline
\end{tabular}


Table 2. VTE's risk factors.

\begin{tabular}{ccc}
\hline VTE's risk factors & Effectives & Percentage \\
\hline Major surgery ( $>45$ minutes) & 70 & 87.5 \\
Minor surgery & 10 & 12.5 \\
age $>40$ years & 58 & 72.5 \\
Obesity (BMI $>25)$ & 22 & 27.5 \\
Sepsis $(<1$ month) & 1 & 1.3 \\
Stroke (<1 month) & 1 & 1.3 \\
Bed rest $(>72$ hours) & 25 & 31.2 \\
Oral contraceptives or hormone replacement therapy & 2 & 2.5 \\
Pregnancy or postpartum $(<1$ month) & 1 & 1.3 \\
History of unexplained stillborn infant, recurrent spontaneous & 2 & 2.5 \\
abortion $(\geq 3)$ & 1 & 33.8 \\
Malignancy & 1.3 \\
Central venous access & 1 & 1.3 \\
History of VTE & 1 & 1.3 \\
Paralysis & 1 &
\end{tabular}

Table 3. Surgical interventions performed.

\begin{tabular}{|c|c|c|}
\hline Intervention performed & Effective & Percentage \\
\hline Gastrectomy & 9 & 11.2 \\
\hline Cholecystectomy & 7 & 9 \\
\hline Gastro-entero-anastomosis & 7 & 9 \\
\hline Colectomy & 6 & 7.7 \\
\hline Thyroidectomy & 10 & 12.5 \\
\hline Restoration of digestive continuity & 8 & 10 \\
\hline Mastectomy & 5 & 6.2 \\
\hline Cure of eventration & 5 & 6.2 \\
\hline Hernia cure & 1 & 1.2 \\
\hline Cephalic duodeno-pancreatectomy & 3 & 3.7 \\
\hline Feeding gastrostomy & 3 & 3.7 \\
\hline Colostomy & 2 & 2.5 \\
\hline Neck lipoma resection & 1 & 1.2 \\
\hline Hysterectomy & 4 & 5 \\
\hline Splenectomy & 1 & 1.2 \\
\hline Adrenalectomy & 1 & 1.2 \\
\hline Nephrectomy & 1 & 1.2 \\
\hline Tubal plasty & 1 & 1.2 \\
\hline Appendicectomy & 1 & 1.2 \\
\hline
\end{tabular}


Continued

\begin{tabular}{ccc}
\hline Annexectomy & 1 & 1.2 \\
Cystogastric anastomosis & 1 & 1.2 \\
Removal of Wirsung stones & 1 & 1.2 \\
Bilio-digestive bypass & 1 & 1.2 \\
Total & 80 & 100 \\
\hline
\end{tabular}

Table 4. Prevention of VTE according to risk level.

\begin{tabular}{ccccccc}
\hline Prophylaxis & \multicolumn{3}{c}{ LMWH } & \multicolumn{4}{c}{ Early Mobilization } \\
\cline { 2 - 7 } Risk level & Yes & No & Total & Yes & No & Total \\
\hline Low & 00 & 03 & 03 & 03 & 00 & 03 \\
Moderate & 01 & 12 & 13 & 13 & 00 & 13 \\
High & 14 & 20 & 34 & 32 & 02 & 34 \\
Highest & 16 & 14 & 30 & 26 & 04 & 30 \\
Total & 31 & 49 & 80 & 74 & 06 & 80 \\
\hline
\end{tabular}

Table 5. The 30-day postoperative outcomes.

\begin{tabular}{ccc}
\hline Outcomes & Effectives & Percentage \\
\hline Simple & 74 & 92.5 \\
Deep vein thrombosis of the lower limbs & 3 & 3.75 \\
Pulmonary embolism and death & 2 & 2.5 \\
Hemorrhagic shock and death & 1 & 1.25 \\
Total & 80 & 100 \\
\hline
\end{tabular}

suffered from VTE; all these patients had a highest risk level of venous thromboembolism. Among them, 02 patients died suddenly from pulmonary embolism.

\section{Discussion}

The need to prevent venous thromboembolism in surgical patients is based on the high incidence of these pathologies postoperatively and their negative impact on morbidity and mortality. The study carried out by Caprini which resulted in the stratification of thromboembolic risks estimates that the incidence of DVT varies from less than $10 \%$ for a low level of risk (score $0-1$ ), to $40 \%-80 \%$ for a level highest risk [8] [9].

The risk of VTE after surgery is the result of the risk associated with the patient (the site, the disease) and the risk specific to the procedure. The main risk factors found in our study were major surgery $(87.5 \%)$, age $>40$ years $(72.5 \%)$, bed rest $(68.8 \%)$, malignancy $(33.8 \%)$ and obesity (27.5\%). Similar results have been reported in surgical patients in several studies in Africa and the rest of the 
world [5] [10] [11]. The risk of thromboembolism was high or highest (Caprini score $\geq 3$ ) in most of our patients $(80 \%)$. A similar result is found in the Bilgi study in India with $71.7 \%$ [10]; on the other hand, this result was higher than that reported in surgery in Cotonou by Houénassi (33\%). However, this latest study showed that VTE's risk was moderate to high in $72 \%$ of cases [5]. The difference could be explained by the profiles of the patients treated in these departments.

Thus, the majority of surgical patients have thromboembolic risk levels that require perioperative prevention of VTE [5] [8] [10] [11].

Postoperative thromboprophylaxis was mainly based on early patient mobilization in our study (92.5\%). It was used as the sole prophylaxis strategy in $64 \%$ of patients in India in the Chandrakumar study [11]. This could be explained by the fact that it is the preventive means which is the easiest and the least expensive to carry out. Current studies support that early postoperative rehabilitation and outpatient surgery have a positive impact on reducing postoperative thromboembolic events [1] [12]. We did not use elastic compression stockings or intermittent pneumatic compression (IPC) in our study, possibly for two reasons: physician habits and equipment unavailability. For the same reasons, only 7\% of health professionals in Ouagadougou in 2014 declared to use mechanical means [13].

The Use LMWH in general or abdominal surgery, reduces the risk of clinical VTE by approximately $70 \%$. In addition, this prophylaxis is associated with a significant reduction in the risk of death from any cause [9]. According to the ninth ACCP' Consensus, pharmacological prophylaxis with low dose LMWH or unfractionated heparin is recommended in patients at moderate or high risk of thromboembolism (Caprini score $\geq 3$ ) who do not present a high risk of bleeding complications [9].

The prescription of pharmacological prophylaxis is very dependent on the financial means of patients, which are often low in our context [13] [14]. This, even if it was not demonstrated in our study, could partly explain the low rate of patients who received this prophylaxis (38.8\%) when it was necessary for $80 \%$ of patients. This result is consistent with that of a Moroccan multicenter study carried out in 2014, in which thromboembolic prophylaxis was recommended in $73 \%$ of surgical patients but it was only performed in $39.3 \%$ of patients [15]. In Benin, the frequency of thromboprophylaxis was $28.5 \%$ in surgery [5]. According to the multinational ENDORSE study, only $58.5 \%$ of surgical patients received appropriate prophylaxis [2].

The duration of drug prophylaxis is fairly well defined in international recommendations and is usually 10 to 15 days postoperatively except in the case of major malignancy surgery for which it is recommended to continue thromboprophylaxis for 4 to 5 weeks [1] [8] [9]. Respecting this duration of treatment also seems problematic in our context. It was an average of 3.4 days in our study (with a maximum of 10 days), most often corresponding to the time it took for the patient to actively ambulate. There was no post-hospital prophylaxis for any 
patient. In Burkina, $65.7 \%$ of health professionals affirmed to maintain the prophylaxis until the mobilization of the patients [13]. In Togo, it was less than 07 days [14]. Compliance with the recommendations in our contexts seems to come up against several obstacles including: the high cost and the unavailability of treatment resources, the lack of a thromboprophylaxis practice protocol, the difficulties in identifying patients at risk, insufficient knowledge of the recommendations in this area [10] [13] [14] [16]. A South African study evaluating the impact of communication for improving the practices of health professionals has shown that it allows a significant increase in the frequency of thromboprophylaxis in patients at risk, which increased from $4.6 \%$ to $36 \%$ [16]. In addition, studies support that the development of outpatient surgery and rapid rehabilitation after surgery (RRAS) has a positive impact on the efficacy of postoperative pharmacological thromboprophylaxis and would reduce its duration and therefore the cost of treatment [1].

In the absence of effective postoperative thromboprophylaxis, the incidence of VTE increases dramatically with increasing Caprini score. The overall incidence of VTE was $6.3 \%$ in our study. All of these thromboembolic events occurred in patients who had highest risk level of thromboembolism. Bilgi reported a similar result with an overall incidence of VTE at 30 days of $7.3 \%$, however, he observed no cases of pulmonary embolism [10]. Mortality ranges from $1 \%$ to $5 \%$ in patients with a Caprini score $\geq 5$ [9]. In our study, two of 30 patients with a highest risk level of thromboembolism died from pulmonary embolism.

\section{Conclusion}

Venous thromboembolism disease is a serious, fatal and frequent disease in surgical settings. The recommended preventive measures are insufficiently applied in our context. Mastering the assessment of the perioperative thromboembolic risk and rigorous application of prophylactic measures will improve the quality of care.

\section{Conflicts of Interest}

The authors declare no conflict of interest regarding the publication of this paper.

\section{References}

[1] Talec, P., Gaujoux, S. and Samama, C.M. (2016) Early Ambulation and Prevention of Post-Operative Thrombo-Embolic Risk. Journal of Visceral Surgery, 153, S11-S14. https://doi.org/10.1016/j.jviscsurg.2016.09.002

[2] Cohen, A.T., Tapson, V.F., Bergmann, J.-F., et al. (2008) Venous Thromboembolism Risk and Prophylaxis in the Acute Hospital Care Setting (ENDORSE Study): A Multinational Cross-Sectional Study. The Lancet, 371, 387-394. https://doi.org/10.1016/S0140-6736(08)60202-0

[3] Bergmann, J.F., Lloret-linares, C., Rami, A., Cohen, A.T., Garay, R.P., Kakkar, A.K., et al. (2011) Risque thromboembolique veineux et pratique de prévention hospita- 
lière: Résultats obtenus en France de l'étude internationale ENDORSE. La Presse médicale, 40, e528-E537. https://doi.org/10.1016/j.lpm.2011.06.023

[4] Kingue, S., Bakilo, L., Minkande, J.Z., Fifen, I., Gureja, Y.P., Razafimahandry, H.J.C., et al. (2014) Epidemiological African Day for Evaluation of Patients at Risk of Venous Thrombosis in Acute Hospital Care Settings. Cardiovascular Journal of Africa, 25, 159-164. https://doi.org/10.5830/CVJA-2014-025

[5] Houénassi, D.M., Tchabi, Y., Yovo, R.A.D., Vehounkpe-Sacca, J., Lawson, M. and Moevi, A.H. (2009) Prevention of Venous Thromboembolism among Inpatients at Cotonou Teaching Hospital, Benin. Archives of Cardiovascular Diseases, 102, 5-9. https://doi.org/10.1016/j.acvd.2008.10.009

[6] Collins, R., Scrimgeour, A., Yusuf, S. and Petor (1988) Réduction de l'embolie pulmonaire fatale et de la thrombose veineuse par administration péri opératoire d'héparine sous cutanée, Aperçu des résultats d'essais randomisés en chirurgie général, de chirurgie orthopédique et urologique. The New England Journal of Medicine, 318, 1162-1173. https://doi.org/10.1056/NEJM198805053181805

[7] Bahl, V., Hu, H.M., Henke, P.K., Wakefield, T.W., Campbell, D.A. and Caprini, J.A. (2010) Etude de validation d'une méthode de notation du risque de thromboembolie veineuse rétrospective. Université des Michigan aux USA. Annale de Chirurgie, 251, 344-350. https://doi.org/10.1097/SLA.0b013e3181b7fca6

[8] Caprini, J.A. (2005) Thrombosis Risk Assessment as a Guide to Quality Patient Care. Disease- $A$-Month, 51, 70-78. https://doi.org/10.1016/j.disamonth.2005.02.003

[9] Gould, M.K., Garcia, D.A., Wren, S.M., et al. (2012) Prevention of VTE in Nonorthopedic Surgical Patients. Antithrombotic Therapy and Prevention of Thrombosis, 9th ed: American College of Chest Physicians Evidence-Based Clinical Practice Guidelines. Chest, 141, e227S-e277S. https://doi.org/10.1378/chest.11-2297

[10] Bilgi, K., Muthusamy, A., Subair, M., Srinivasan, S., Kumar, A. and Ravi, R. (2016) Assessing the Risk for Development of Venous Thromboembolism (VTE) in Surgical Patients Using Adapted Caprini Scoring System. International Journal of Surgery, 30, 68-73. https://doi.org/10.1016/j.ijsu.2016.04.030

[11] Chandrakumar, A., Sajid, A.M., Suriyaprakash, T.N. and Ajmal, K.K. (2016) Prevalence of Venous Thromboembolism Risk Factors and Prophylactic Adequacy among General Surgical Patients in a Tertiary Care Hospital. Indian Heart Journal, 68, 513-518. https://doi.org/10.1016/j.ihj.2015.12.003

[12] Samama, M. (2019) Cas particuliers des chirurgies à haut risque thrombotique: Chirurgie orthopédique (fractures du bassin, fractures du plateau tibial), chirurgie bariatrique, chirurgie tumorale abdomino-pelvienne. JMV-Journal de Médecine Vasculaire, 44, 99. https://doi.org/10.1016/j.jdmv.2018.12.009

[13] Naibe, D.T., Samadoulougou, A., Kabore, H., Yameogo, R.A., Millogo, G., Yameogo, N.V., et al. (2014) Pratique de la prophylaxie de la maladie thromboembolique veineuse: Enquête réalisée auprès des professionnels de santé de la ville de Ouagadougou. Pan African Medical Journal, 19, 395.

https://doi.org/10.11604/pamj.2014.19.395.5474

[14] Ouro-Bang'na Maman, A.-F., Agbétra, N., Abalo, A., Egbohoua, P., Tomtaa, K. and Choblid, M. (2006) Pratique de la prophylaxie de la maladie thromboembolique veineuse: Enquête auprès des chirurgiens et anesthésistes au Togo. Annales Françaises d Anesthésie et de Réanimation, 25, 1107-1110. https://doi.org/10.1016/j.annfar.2006.06.020

[15] Khaleq, K. (2014) Audit sur la prévention de la maladie thromboembolique postopératoire au Maroc. Annales Françaises d'Anesthésie et de Réanimation, 33, A188. 
https://doi.org/10.1016/j.annfar.2014.07.307

[16] Beutel, B.G. and Jenkins, L.S. (2015) Preventing Venous Thromboembolism at a District Hospital: A Quality Improvement Study. South African Family Practice, 57, 64-68. https://doi.org/10.1080/20786190.2014.977033 